\title{
Being Left
}

\author{
Dean Schuyler, M.D.
}

$\mathrm{I}$

n my book A Practical Guide to Cognitive Therapy, I discuss falling in love. Part of this process involves the "forming of an icon," in which all the idealized beliefs about a loved one are represented. When a relationship dissolves, grieving the actual loss is often not the hardest part. Rather, the loss of all the hopes, the dreams, and even some misrepresentations-the "dismantling of the icon"-is often the biggest challenge of all. When the icon persists, the capability to move on with one's life may be delayed and depression may overtake grieving. This, I believe, is the case with Susan, a 28 -year-old woman who consulted me for brief psychotherapy recently.

\section{CASE PRESENTATION}

Susan's chief complaint was "I'm having a hard time being a separated single parent." She had moved to Charleston, South Carolina, from Dallas, Texas, 3 months after Phillip, her husband of 8 years, left her. Their daughter was then 18 months old. Phillip claimed he was "unhappy being married and didn't want to be a father." After Susan related her story during a visit to her primary care doctor for a routine physical examination, the doctor referred her to me.

Susan knew Phillip from the time they were 10 years old (in fourth grade). Her parents divorced when she was 10 , and her father (to whom she remained very close) died in a construction accident at work when she was twenty. She dated one boy in high school for 3 years. The relationship ended when he died in a motorcycle accident. At this point, Phillip became a "close friend" and "took care of her." They married when they were each 19, and she worked to support them while he went to law school. Susan described herself as someone who "takes responsibility for, and tries to fix, people." She was her mother and father's only child.

After graduating from high school, Susan took college classes for 3 years while working. She had worked in Charleston for the past 6 months as office manager for an accounting firm. Periodically in the past year, she had "shut down" because of stress. She would withdraw, have disrupted sleep, overeat, get exhausted due to lack of energy, and be unable to focus at work. She was unhappy about being alone and did not really understand how Phillip could have left her and their daughter.

Her goal for therapy was to learn how to deal with her situation without falling apart. The diagnosis was major depression. She wanted a "problem-solving therapy, without medication." She had no history of alcohol or drug abuse.

\section{PSYCHOTHERAPY}

I explained the cognitive therapy model to her, with its focus on meanings, beliefs, and options. She defined her problems as (1) dealing with separation, (2) dealing with being a single parent, and (3) formulating a life plan.

$3 \mathrm{We}$ worked first on establishing an explanation for the separation. We examined how she understood her situation and her ideas about Phillip's thinking. I used analogies and some self-disclosure early on to help her focus when she could not look profitably at her own situation. The material came from the lives of friends of mine and then from my own life. Sometimes people can see a concept more easily in the context of a life other than their own. She rapidly engaged in the therapy process, forming a genuine connection to me as a helping agent.

When Phillip came for a 1-week visit "with his daughter," we discussed her expectations. Only afterward did she reveal her belief that "he would stay and reconcile." Her anger at him was evident after he left. She blamed Phillip for "screwing up their life and taking no responsibility for it." I encouraged her to keep a log of her strong reactions, in the form of a triple column: situations, feelings, and thoughts. Each of the next several sessions began with examining her homework.

In session 5, she created an elaborate agenda for herself that began her thinking about a life plan. It urged her to get out more, work out, make some new friendships, take time to play the piano, and, also, "get over Phillip." We discussed strategies for achieving her goals, referring back constantly to the meanings she assigned to events. 
By session 6 (after 3 months), she reported sleeping and eating better and having more energy and a markedly better mood. We discussed her view of dating and some parenting options for her little daughter. Using a format of choices and consequences, she related her plan to move to a new house in 1 month. She had gone looking with a girlfriend and had offered a contract that was accepted. She discussed potential relationships with men, her reinvigorated view of herself, and her pride in her daughter's milestones.

At session 10, she told me how "Phillip was really not good for her." She had embarked on a weight loss program and shed 10 pounds in just 3 weeks. Session 11 occurred after her move, which she viewed as a "real accomplishment" and heralded as a new beginning. We reviewed the changes she had made over the past 5 months. Over

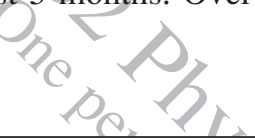

the next 2 sessions, she demonstrated real initiative in social and work situations (previously lacking) and expressed surprise, but felt really good about herself.

Six months and 13 sessions complete, we terminated therapy, discussing her view of what she attributed to herself, to me, and to the therapy process. She wrote to me 1 month later to describe her application to a program to earn a college degree in business. Two months later, a second letter told of her acceptance letter. Three months later, amid talk of success in her classes, a letter described her reaction to Phillip's initiation of divorce proceedings. The most recent letter arrived almost 1 year after our last visit. It spoke in detail about school grades, her daughter's school successes, her stipulations for the divorce, a new job, new friends, and an active social life.

She seemed to be well on her way.

Editor's note: Dr. Schuyler is Clinical Associate Professor of Psychiatry and teaches cognitive therapy to psychiatry residents at the Medical University of South Carolina.

For further reading: A Practical Guide to Cognitive Therapy. 1st ed. By Dean Schuyler, New York, NY: WW Norton \& Co; 1991. ISBN 0393701050 